\title{
QUALITY OF FLAVORED YOGURT CONTAINING ADDED COFFEE AND SUGAR
}

\author{
GÜRDAL TAN and FİGEN KOREL ${ }^{1,2}$ \\ Food Engineering Department \\ Celal Bayar University \\ Manisa, Turkey
}

\begin{abstract}
Yogurts flavored with instant coffee (0.5, 0.7 and 0.9\%) and sweetened with sugar (4 or 5\%) and a control yogurt (no coffee or sugar) were evaluated for chemical, physical, microbiological and sensory properties. The added ingredients generally had no effect on the chemical, physical and microbiological quality of yogurts at day 1 after preparation as compared to the control. During 15 days at 5-7C, pH and lactic acid bacteria counts decreased $(\mathrm{P}<0.05)$ and titratable acidity increased $(\mathrm{P}<0.05)$ in all samples. Yogurts with $0.5 \%$ coffee flavoring and 4 and $5 \%$ sugar met Turkish Institute Standards for yogurt sensory quality when evaluated by a trained 10-member panel. Yogurt flavored with $0.5 \%$ coffee and containing 5\% sugar had most attributes rated in the "like" category by 50\% or more of 51 consumer panelists.
\end{abstract}

\section{PRACTICAL APPLICATIONS}

Worldwide consumption of yogurt is increasing. This increase is largely attributed to the altering of plain yogurt with unique flavors. Since flavors are important factors affecting consumers' acceptability of the product, this research explores the possibility of utilizing instant coffee and sugar to produce an acceptable flavored yogurt.

${ }^{1}$ Present address: İzmir Institute of Technology, Food Engineering Department, Urla, İzmir 35430 Turkey.

${ }^{2}$ Corresponding author. TEL: +90-232-7506228; FAX: +90-232-7506196. EMAIL: figenkorel@ iyte.edu.tr 


\section{INTRODUCTION}

Yogurt is a milk product fermented with a mixture of Lactobacillus delbrueckii subsp. bulgaricus and Streptococcus thermophilus which convert lactose into lactic acid (Tamime and Marshall 1997). Yogurt has high nutritional value and is a good source of carbohydrate, protein, fat, vitamins, calcium and phosphorus (Renner and Saldaml1 1983). The major cited nutritional and health benefits of consuming yogurt are reduction in the incidence of lactose intolerance and gastrointestinal illnesses, provision of immunostimulatory effects, antitumor and anticholesterol activity, and providing some protection from pathogens due to the presence of live, active starter cultures (Labell 1989; Kurmann et al. 1992; Chandan and Shahani 1993, 1995; Chandan 1999).

Worldwide consumption of yogurt is increasing (Chandan and Shahani 1993, 1995). In the U.S.A., per capita consumption of yogurt has registered significant growth and was $3.7 \mathrm{~kg}$ in 2003 with an increase of 39\% in 19962003 (International Dairy Foods Association 1997; NASS 2006). In Turkey, most of the milk produced is used for yogurt production and the estimated annual Turkish consumption of yogurt in 2000 was approximately 1.9 million tons (Tan and Ertürk 2002). This high annual consumption rate is observed because plain set-type yogurt is one of the basic staples of the diet.

The increase of yogurt consumption worldwide is largely attributed to altering plain yogurt for unique flavors, desirable textures, and maintaining excellent nutritional profiles and healthy food values. Flavors are important factors affecting consumers' acceptability of the product. Different flavors, such as strawberry or vanillin, have been used in yogurt production (Kora et al. 2004; Lubbers et al. 2004). In fact, refrigerated flavored yogurt market share in the U.S.A. was $94.2 \%$, compared to a market share of $5.8 \%$ for plain yogurt. Vanilla flavored yogurt held a market share of $7.1 \%$ among the flavored yogurt category in 2001 (Orgish 2002). This has provided consumers with a novel array of flavors and multiple textures that supported marketing and merchandising practices (Shahani and Chandan 1979; Chandan and Shahani 1993; Orgish 2002).

Yogurt manufacturers produce yogurts having a desirable quality by selecting specific ingredients in accordance with consumer demand. Because yogurt is a popular food choice for adults and children, yogurt products with various flavors, colors and thickness have increased their market share (Gorski 1997; Cvetan 1998). Öztürk and Öner (1999) produced and evaluated yogurt containing concentrated grape juice. Keating and White (1990) evaluated alternative sweeteners in plain and fruit-flavored yogurts and Ayar et al. (2001) also produced several fruit-flavored yogurts and evaluated their chemical and sensory properties. Carbonated yogurt was produced and evaluated for sensory 
properties and consumer acceptance by Karagül-Yüceer et al. (1999). With respect to these studies, the possibility exists that yogurt flavored with coffee might also attract consumers who are searching for new and unique products. On the other hand, the reason for choosing coffee as flavoring agent in yogurt production is that most people drink coffee several times a day and if a yogurt is linked with coffee flavor, this would increase consumers' attraction as well as yogurt consumption. Addition of sugar is necessary to mask the bitter taste of coffee and also because sweetness is preferred by consumers in flavored yogurts (Vickers et al. 2001).

The objectives of this study were to evaluate the addition of coffee flavoring in sweetened yogurts on overall quality (chemical, physical and microbiological) and to conduct sensory evaluations of the products using a trained panel followed by a consumer panel. For the consumer panel, determining the acceptability of the newly formulated coffee flavored yogurt which has met the yogurt standards of the Turkish Standards Institute (1989) was an objective.

\section{MATERIALS AND METHODS}

\section{Yogurt Production}

In each of two replications, pasteurized milk was obtained from Pınar Süt Company (Izmir, Turkey) in 1-L packages having the same lot number and "sell-by" date. The pasteurized milk was heated to 50C and 5\% (w/v) skim milk powder (Pınar Süt Company) was added to increase the total solids content to provide better consistency, texture and creaminess. Control samples (for no flavoring or sugar addition) were then separated and the rest of the milk was divided into two groups. Each group was mixed with either 4 or $5 \%(w / v)$ sugar. Control samples and the sweetened groups were cooled to $42-43 \mathrm{C}$ in an ice-water bath. The sweetened groups were then subdivided into three subgroups and $0.5,0.7$ or $0.9 \%$ (w/v) of instant coffee (Nescafe Gold, Nestlé, Bursa, Turkey), as flavoring, was added to each subgroup. The coffee and sugar concentrations were selected based on results of preliminary sensory evaluations. Neither coffee nor sugar was added to control samples. All mixes, including the control $(n=7)$, were inoculated with $3 \%(\mathrm{w} / \mathrm{v})$ of freeze-dried starter culture containing strains of $L$. delbrueckii subsp. bulgaricus and S. thermophilus (Wiesby 709 and V1, Niebüll, Germany) in a 1:1 ratio. Aliquots of $100 \mathrm{~mL}$ of each subgroup mix and the control were transferred to $160-\mathrm{mL}$ sterilized glass jars and incubated at $42 \mathrm{C}$ until $\mathrm{pH} 4.7$ was attained. The average incubation time was approximately $3 \mathrm{~h}$. After precooling at ambient temperature for $30 \mathrm{~min}$, the yogurts were stored at 5-7C and analyzed at days 1 or days $1,4,7,11$ and 15 as stated later. 


\section{Chemical and Physical Analyses}

The specific gravity of milk was determined using a standard hydrometer by method 925.22 of the AOAC (1999). Total solids of milk and yogurt samples at day 1 were measured gravimetrically (Turkish Standards Institute 1989; AOAC 1999). Fat content of milk and yogurts at day 1 were assessed by butyrometers using the Gerber method (Turkish Standards Institute 1989). Protein content at day 1 was determined by Kjeldahl method 991.20 of the AOAC (1999) using 6.38 as the nitrogen conversion factor. Specific gravity, fat and protein determined in duplicate and total solids were determined in triplicate.

Yogurt $\mathrm{pH}$ was measured in duplicate using a Hanna Instruments HI9321 Microprocessor model $\mathrm{pH}$ meter (Porto, Portugal). Titratable acidity of milk and the yogurts, expressed as \% lactic acid, was determined on triplicate samples following method 947.05 of the AOAC (1999). Yogurt $\mathrm{pH}$ and titratable acidity were measured at days 1, 4, 7, 11 and 15 .

Syneresis of yogurt samples at day 1 was determined in duplicate as described by Rodarte et al. (1993). Each sample (10 g) was centrifuged in a Hettich Model EBA 8S centrifuge (Tuttlingen, Germany) at 5,000 rpm for $20 \mathrm{~min}$. The clear supernatant was decanted and measured. Syneresis $(\%)$ was based on the volume of clear supernatant per 100-mL yogurt.

Apparent viscosity was measured using an LVDV-I Brookfield viscometer (Middleboro, MA) equipped with a number 3 spindle and operated at a speed of $10 \mathrm{rpm}$ (Gassem and Frank 1991). Duplicate samples of $160 \mathrm{~mL}$ of yogurt at day 1 at ambient temperature were stirred for $1 \mathrm{~min}$ before measurement because the yogurts were set-type and not stirred yogurts. Apparent viscosity was recorded in centipoise.

\section{Lactic Acid Bacteria (LAB) and Yeast and Mold Counts}

Total LAB counts were determined for the starter culture and yogurt samples. Aliquots of $10 \mathrm{~g}$ were diluted with $90-\mathrm{mL}$ sterile peptone water $(0.1 \% \mathrm{w} / \mathrm{v})$ and serial dilutions were prepared. Mann, Rogosa, Sharpe agar (Oxoid, Basingstoke, U.K.) was used for assaying total lactic acid bacteria by the double layer plating technique. Plates were incubated at 32C for 48-72 h (Hausler 1974; Speck 1976). Yeast and mold counts were also conducted on the yogurts. The serial dilutions were plated on potato dextrose agar (Oxoid) acidified with $1 \%$ lactic acid and the plates were incubated at 30C for 5 days (Sharf 1966). All yogurt samples were duplicate plated at days 1, 4, 7,11 and 15. Microbial counts were expressed as $\log _{10}$ colony forming units (cfu) per $\mathrm{mL}$ or per $\mathrm{g}$, depending on the sample. 


\section{Sensory Analysis}

All prepared yogurt samples were evaluated at day 1 by a 10 -member trained sensory panel. Panelists who were frequent yogurt consumers were selected from graduate students and faculty in the Food Engineering Department at Celal Bayar University and consisted of five females and five males (aged 25-45). Panelists were trained in a group discussion with commercial reference samples of fresh plain yogurt which was obtained from retail markets. Verbal descriptors (Table 1) which were modified from the Yogurt Standard (TS1330) of the Turkish Standards Institute (1989) had been discussed during training. After training, one session was conducted to verify the effectiveness of the training and in this session a fresh plain yogurt sample was presented to each panelist for scoring appearance, consistency on the spoon, consistency in the mouth, flavor and overall acceptability. Experimental yogurts were coded (three digits randomly selected) and presented to panelists at ambient temperature in $160-\mathrm{mL}$ glass jars under typical daylight room conditions. Panelists independently evaluated each sample for appearance, odor, consistency on the spoon, consistency in the mouth, flavor and overall acceptability using a descriptive hedonic scale (scale of 1-5 with 5 being the highest attribute score) as shown in Table 1. Samples were randomly ordered at the beginning of the panel and each panelist received the samples in the same order. Only coffee-flavored yogurt samples were given to the panelists during the panel session, not fresh plain yogurt. Two replicate evaluation sessions were conducted.

Based on the results of the trained panel, a consumer acceptance panel was also conducted using the experimental yogurt, which had the highest total score from trained panel, prepared with $0.5 \%$ coffee flavoring and sweetened with $5 \%$ sugar. Consumer panelists $(n=51)$ were chosen from other undergraduate and graduate students in the Food Engineering Department at Celal Bayar University (29 females and 22 males, aged 21-30). The yogurt was presented in a 160 -mL glass jar. Panelists scored how they either liked or disliked the appearance, odor and consistency (in the mouth), flavor and overall acceptability using a hedonic scale $(5=$ like very much; $3=$ neither like nor dislike; $1=$ dislike extremely). This panel was conducted once.

\section{Data Analysis}

Two replications were conducted for all analyses and the trained sensory evaluation. Results of the chemical, physical and microbial analyses of the yogurts and of the trained sensory panel evaluation were analyzed by analysis of variance using PROC GLM procedure of SAS (1998). Means with a 
TABLE 1.

DESCRIPTIVE HEDONIC SCALE USED FOR SENSORY EVALUATION OF YOGURT SAMPLES*

\begin{tabular}{|c|c|c|}
\hline Sensory attributes & Descriptions of the attributes & Score \\
\hline \multirow[t]{4}{*}{ Appearance } & $\begin{array}{l}\text { Glossy, no whey (liquid) separation occurred, no } \\
\text { cracks and gas bubbles, clean appearance, } \\
\text { homogeneous }\end{array}$ & 5 \\
\hline & No whey separation, no cracks and gas bubbles & 4 \\
\hline & $\begin{array}{l}\text { Dull, few cracks, some whey separation occurred, } \\
\text { clean appearance }\end{array}$ & 3 \\
\hline & $\begin{array}{l}\text { Many cracks and gas bubbles, whey separation } \\
\text { occurred, dirty appearance }\end{array}$ & $1-2$ \\
\hline \multirow[t]{3}{*}{ Odor } & $\begin{array}{l}\text { Having specific (normal) yogurt odor (as well as } \\
\text { coffee odor) }\end{array}$ & $4-5$ \\
\hline & Not having normal yogurt odor & 3 \\
\hline & $\begin{array}{l}\text { Not having normal yogurt odor and having foreign } \\
\text { odor }\end{array}$ & $1-2$ \\
\hline \multirow[t]{4}{*}{ Consistency on spoon } & $\begin{array}{l}\text { Thick on spoon, having normal texture, homogeneous, } \\
\text { thick after stirring, no immediate whey separation } \\
\text { occurred }\end{array}$ & 5 \\
\hline & $\begin{array}{l}\text { Thick on spoon, having normal texture, thick after } \\
\text { stirring, some whey separation occurred }\end{array}$ & 4 \\
\hline & $\begin{array}{l}\text { Not too fluid on spoon, fluid after stirring, immediate } \\
\text { whey separation occurred }\end{array}$ & 3 \\
\hline & $\begin{array}{l}\text { Free running from spoon, too fluid after stirring, } \\
\text { immediate and much whey separation occurred }\end{array}$ & $1-2$ \\
\hline \multirow[t]{4}{*}{ Consistency in mouth } & Having very good texture, homogeneous & 5 \\
\hline & Having good texture, homogeneous & 4 \\
\hline & Fluid in mouth, not having good texture & 3 \\
\hline & $\begin{array}{l}\text { Too fluid while squeezing one spoonful of the sample } \\
\text { between tongue and palate }\end{array}$ & $1-2$ \\
\hline \multirow[t]{3}{*}{ Flavor } & Normal yogurt flavor as well as coffee flavor & $5-4$ \\
\hline & Sour, some bitterness, having foreign flavor & 3 \\
\hline & Too sour, bitter, having foreign flavor & $1-2$ \\
\hline \multirow[t]{5}{*}{ Overall acceptability } & Excellent & 5 \\
\hline & Good & 4 \\
\hline & Neither good or bad & 3 \\
\hline & $\mathrm{Bad}$ & 2 \\
\hline & Very bad & 1 \\
\hline
\end{tabular}

* Modified from Yogurt Standard (TS1330) of the Turkish Standards Institute (1989).

significant difference $(P<0.05)$ were compared using the Duncan test. Because the consumer panel was conducted only once for yogurt attributes, the percentages of panelists selecting scores in the hedonic range of "like" (scores 4 and 5), "dislike" (scores 1 and 2), and "neither like nor dislike" were reported. 


\section{RESULTS AND DISCUSSION}

\section{Chemical and Physical Analyses}

Pasteurized whole milk used for yogurt production had averages for specific gravity, total solids, fat and protein contents of $1.030 \pm 0.002$, $10.68 \pm 0.53 \%, 3.0 \pm 0.0 \%$ and $2.91 \pm 0.13 \%$, respectively. The Turkish Food Codex (2000) has established minimum requirements for whole milk for specific gravity of $1.028,3 \%$ fat and $2.8 \%$ protein. All the minimum requirements of the milk used for yogurt preparation met these requirements.

Total solids, fat and protein contents for the control yogurt $(0 \%$ coffee and $0 \%$ sugar addition) and the yogurts with added coffee and sugar at day 1 of storage are shown in Table 2. No difference $(P>0.05)$ in total solids existed among the flavored and sweetened yogurts. Fat content of all yogurts also were not different and ranged between 2.6-2.8\%. In the Turkish Food Codex (2001), these yogurts would be classified as half-fat yogurts because the fat contents are required to be at least 1.5 and $3.8 \%$, respectively. Decrease of the fat contents was due to addition of $5 \%(\mathrm{w} / \mathrm{w})$ of skim milk powder in yogurt preparation. This addition also increased the protein content of the yogurts, ranging from $4.1-4.4 \%$.

Syneresis, based on the centrifugal method of Rodarte et al. (1993), differed $(P<0.05)$ among yogurts and was highest $(54.4 \%)$ in the control yogurt and lowest (49.4 to $49.5 \%$ ) in yogurts with $5 \%$ added sugar and 0.5 or $0.7 \%$ added coffee. All yogurts containing $4 \%$ added sugar did not differ $(P>0.05)$. Added sugar appeared to aid in reducing syneresis except in yogurt containing $0.9 \%$ coffee flavoring. Syneresis results of this study are in general agreement with the findings of the following studies. Gassem and Frank (1991) reported yogurt syneresis of between 20-60\% and Rodarte et al. (1993) stated syneresis values ranging from $20-80 \%$. Syneresis of yogurt with added concentrated grape juice, which is acidic, was reported as $43 \%$ by Öztürk and Öner (1999).

Apparent viscosities of the control and flavored-sweetened yogurts (Table 2) were measured after being stirred and ranged from 1,755 to 2,390 cp. Although there were some differences $(P<0.05)$ among the yogurts, the reason for the viscosity differences could not be explained. Keating and White (1990) reported that apparent viscosities of yogurts (stirred for $20 \mathrm{~s}$ ) prepared with various sweeteners ranged from 3,600 to 5,200 cp. Öztürk and Öner (1999) stated that the initial apparent viscosity of yogurt containing concentrated grape juice was 3,660 cp. Yogurt produced using milk treated with proteolytic enzymes (Gassem and Frank 1991) was in the range of 3,000-4,000 cp at day 1. Rodarte et al. (1993) stated that apparent viscosities of yogurts varied from 800 to $4,200 \mathrm{cp}$ depending on the starter cultures used and the total solids content. 


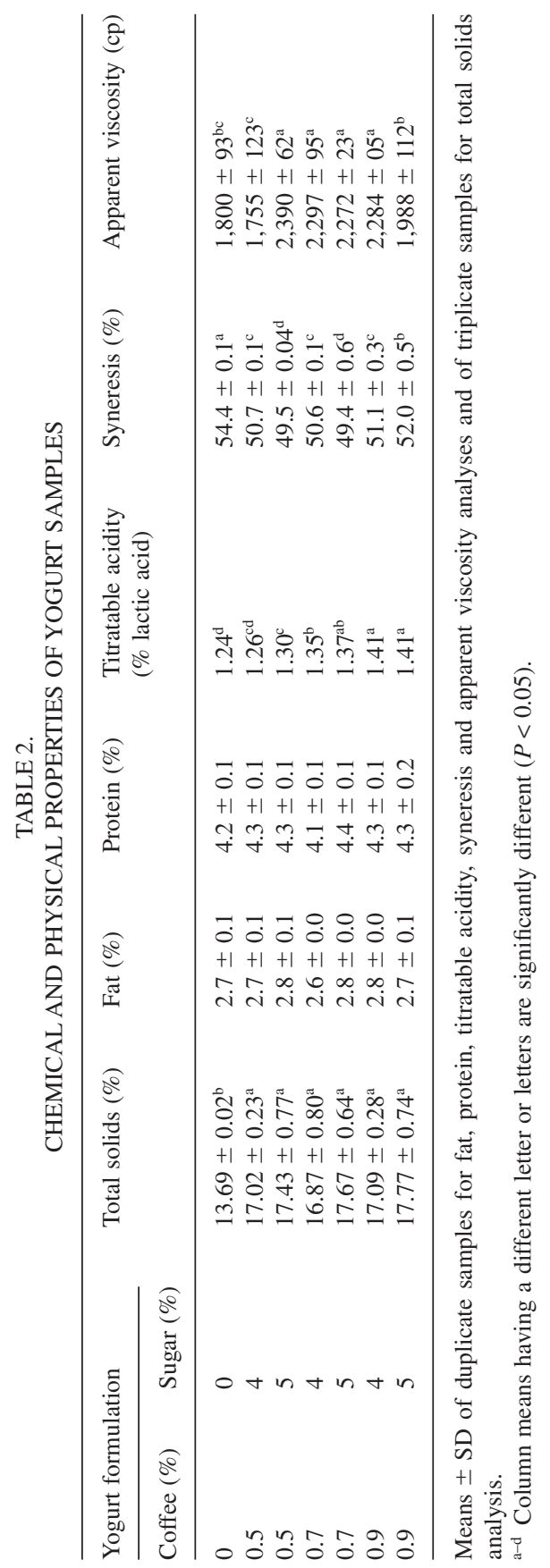


TABLE 3.

YOGURT $\mathrm{pH}$ AND TITRATABLE ACIDITY OVER ALL SAMPLES DURING 15 DAYS OF REFRIGERATED STORAGE

\begin{tabular}{lll}
\hline Storage time (days) & $\mathrm{pH}$ & $\begin{array}{l}\text { Titratable acidity } \\
\text { (\% lactic acid) }\end{array}$ \\
\hline 1 & $4.56^{\mathrm{a}}$ & $1.22^{\mathrm{z}}$ \\
4 & $4.46^{\mathrm{a}}$ & $1.30^{\mathrm{y}}$ \\
7 & $4.34^{\mathrm{b}}$ & $1.36^{\mathrm{x}}$ \\
11 & $4.29^{\mathrm{bc}}$ & $1.36^{\mathrm{x}}$ \\
15 & $4.21^{\mathrm{c}}$ & $1.42^{\mathrm{w}}$ \\
\hline
\end{tabular}

Means of duplicate samples for $\mathrm{pH}$ and of triplicate samples for titratable acidity.

${ }^{a-c}$ Column means with different letters are significantly different $(P<0.05)$.

${ }^{\mathrm{w}-\mathrm{z}}$ Column means with different letters are significantly different $(P<0.05)$.

Titratable acidity (as lactic acid) of milk used for yogurt preparation was $0.136 \%$ and was within the range of $0.135-0.200 \%$ given in the Turkish Food Codex (2000). Titratable acidity of the yogurt samples differed $(P<0.05)$ among treatments (Table 2$)$. The changes primarily in the instant coffee concentration significantly affected the titratable acidity of the samples. Acidity of the instant coffee could have an effect on this increase. Roasted coffees, from which instant coffee is prepared, was reported to contain 2.2-4.5\% chlorogenic acid (Esteban-Diez et al. 2004) in addition to other organic acids such as acetic, citric and malic (Alcazar et al. 2003). Titratable acidity and $\mathrm{pH}$ of the yogurts (Table 3$)$ differed $(P<0.05)$ during 15 days of refrigerated storage. As yogurt $\mathrm{pH}$ decreased during storage from 4.56 (day 1) to 4.21 (day 15), overall titratable acidity increased from 1.22 to $1.42 \%$. Among yogurts within a storage time, no $\mathrm{pH}$ differences occurred. Öztürk and Öner (1999) reported $\mathrm{pH}$ values for their control yogurt and yogurt with added concentrated grape juice as between 4.40 and 4.45 at day 1 with decreases to $\mathrm{pH} 4.30-4.35$ at day 15 . In this study, the overall decrease of $\mathrm{pH}$ during storage was slightly more than the decrease reported by Öztürk and Öner (1999). Storage temperature may account for this difference. In Öztürk and Öner's (1999) study, yogurts were held at 4C whereas we stored yogurts at 5-7C. The increase of titratable acidities at each storage period generally reflected the decline in yogurt $\mathrm{pH}$ including data for days 7 and 11, which show no changes in that period. Control yogurts in the study of Laye et al. (1993) showed titratable acidity increasing from $1.21 \%$ (at day 2) to $1.40 \%$ (at day 12). Results of the present study are in general agreement with the findings previously reported. 
a
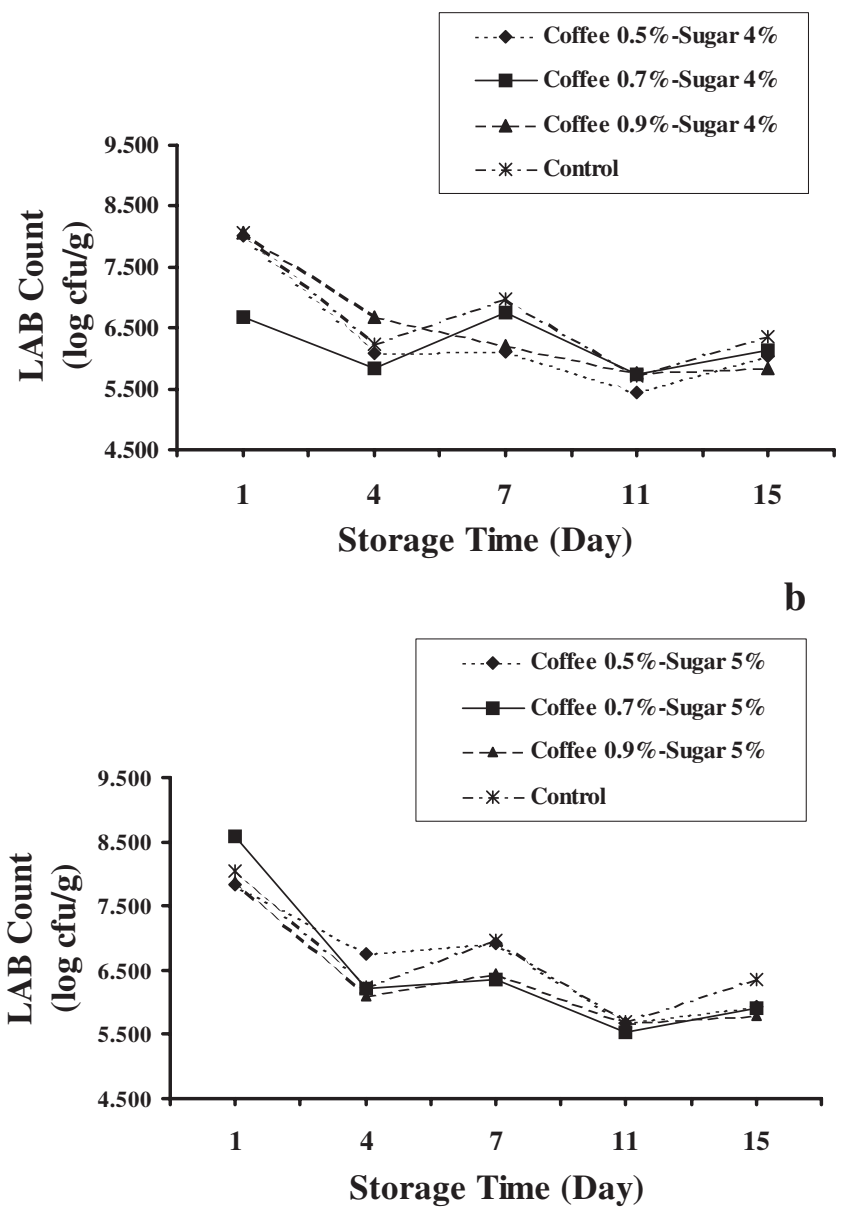

FIG. 1. TOTAL LACTIC ACID BACTERIA COUNTS OF YOGURTS FLAVORED WITH COFFEE AND SWEETENED WITH (a) 4\% SUGAR OR (b) 5\% SUGAR DURING 15 DAYS OF REFRIGERATED STORAGE AT 5-7C

\section{LAB and Yeast and Mold Counts}

The starter culture used in yogurt preparation had a LAB count of $6.8 \pm 0.4 \log \mathrm{cfu} / \mathrm{mL}$. LAB counts of yogurt containing 4 and $5 \%$ added sugar are shown in Fig. 1. LAB counts of yogurts, except yogurt containing $0.7 \%$ coffee and $4 \%$ sugar, at day 1 were higher than $10^{7} \mathrm{cfu} / \mathrm{g}$, which was the minimum limit stated for LAB counts of yogurts in Turkish Food Codex (2001). 
During the 15 days of storage, LAB counts decreased $(P<0.05)$. Addition of coffee and sugar did not affect LAB counts. Çon et al. (1996) reported that LAB counts of fruit-flavored yogurts were $8.9 \mathrm{log} \mathrm{cfu} / \mathrm{g}$ and $8.4 \mathrm{log} \mathrm{cfu} / \mathrm{g}$ at days 1 and 13, respectively, and Akin and Konar (2001) found LAB counts for yogurts made from cows' milk varied between 8.3-8.7 log cfu/g at day 1 and 8.5$8.6 \mathrm{log} \mathrm{cfu} / \mathrm{g}$ at day 15 . In comparison to these reports, LAB counts in this study were generally less and decreased significantly more over the 15-day period. The decrease was possibly related to the slightly higher storage temperature and larger $\mathrm{pH}$ reduction that was observed (Table 3). Yeast and mold counts for the yogurts during 15 days of storage were $<10 \mathrm{cfu} / \mathrm{g}$ sample and they were in agreement with the Turkish Food Codex (2001).

\section{Sensory Analysis}

Appearance, odor and consistency on the spoon were not found different $(P>0.05)$ among the coffee-flavored and sweetened yogurts by the trained 10 -member sensory panel (Table 4). Consistency in the mouth, flavor and overall acceptability differed $(P<0.05)$ among the yogurts with decreasing scores as the level of coffee flavoring increased from 0.5 to $0.9 \%$. Sugar content was less a factor for consistency in the mouth and overall acceptability although scores, while not significantly different, averaged numerically higher for coffee-flavored yogurts with 5\% added sugar compared to $4 \%$. Yogurts with $0.7 \%$ coffee and $4 \%$ sugar and both yogurts with $0.9 \%$ coffee flavoring had the lowest scores for most attributes including overall acceptability. The Yogurt Standard of the Turkish Standards Institute (1989) state that the total score of a yogurt evaluated by panelists is required to be at least 20 based on the sum of the yogurt's appearance, odor, consistency on the spoon, consistency in the mouth and flavor. Only the two experimental yogurts flavored with $0.5 \%$ coffee met this requirement with total score of 20.6 (with $4 \%$ sugar) and 20.9 (with 5\% sugar). Although these two yogurts did not differ in any of the rated attributes, the yogurt with 5\% added sugar was selected for the consumer acceptance panel. Panelists have been shown to rate likeness higher in yogurts with the higher levels of sweetness (Vickers et al. 2001).

The appearance, odor, consistency (in the mouth) and flavor were liked by $71,59,69$ and 50\%, respectively, of the 51 consumer panelists. The overall acceptability of the yogurt flavored with $0.5 \%$ coffee and sweetened with $5 \%$ sugar was rated in the like category by $43 \%$ of the panelists, but $20 \%$ of them reported that they disliked the sample. Remaining panelists (37\%) neither liked nor disliked the sample. These findings from the consumer panel strongly suggest that some Turkish yogurt consumers still prefer to eat plain set-type yogurts, especially with meals. However, flavored yogurts, such as those evaluated in this study, may have potential as a snack item. 


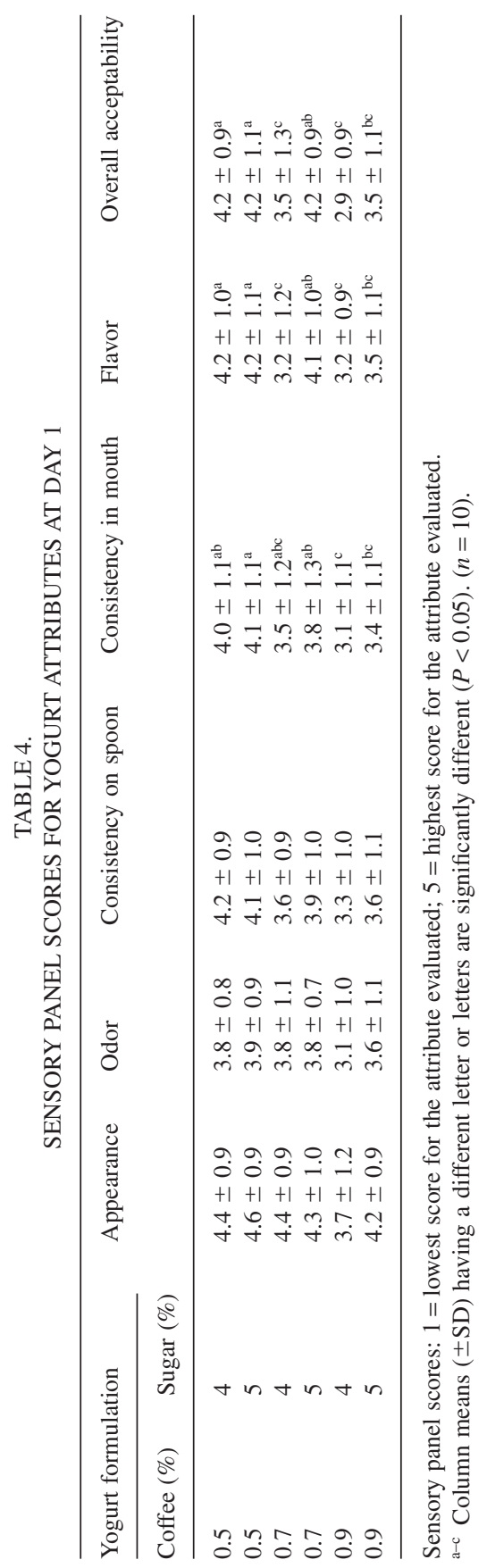




\section{CONCLUSIONS}

Addition of coffee and sugar as flavoring and sweetening ingredients generally had no effect on the chemical, physical and microbiological quality of yogurts at day 1 after preparation as compared to a control yogurt without these ingredients. During 15 days of refrigerated storage, however, yogurt $\mathrm{pH}$ and LAB counts decreased and titratable acidity increased. Based on sensory panel evaluations by trained panelists, yogurts with $0.5 \%$ coffee and 4 or 5\% sugar addition had the highest overall acceptability compared to yogurts flavored with 0.7 and $0.9 \%$ coffee. Yogurt flavored with $0.5 \%$ coffee and containing 5\% sugar had most attributes rated in the "like" category by $50 \%$ or more of consumer panelists. The concentration of added coffee and sugar, as well as the influence of any other ingredient addition such as other sweeteners, would require careful sensory evaluation in development of coffee-flavored yogurts. Further studies with a large consumer group, particularly with coffee consumers, needs to be conducted to determine the best product formulation. As the concentration of coffee increased in the present study, the rate of liking decreased, which could be due to the bitter taste of coffee. Yogurts flavored with coffee and sugar may eventually have a niche role in the dairy products market as consumer trends in tastes change.

\section{ACKNOWLEDGMENTS}

This research was supported by Celal Bayar University research funds, Project No. 2001/23.

\section{REFERENCES}

AKIN, M.S. and KONAR, A. 2001. A comparative study on microbiological qualities of fruit-aroma yogurts made from cow's and goat's milk and stored at 15 days. Gida 26, 121-126.

ALCAZAR, A., FERNANDEZ-CACERES, R.L., MARTIN, M.J., PABLOS, F. and GONZALES, A.G. 2003. Ion chromatographic determination of some organic acids, chloride and phosphate in coffee and tea. Talanta 61 , $95-101$.

AOAC. 1999. Official Methods of Analysis of AOAC International, 16th Ed., 5th rev., AOAC International, Gaithersburg, MD.

AYAR, A., AKIN, N. and TURAN, S. 2001. A research on some chemical and sensory properties of flavored yoghurt prepared with different composition. Gida 2001-10, 65-69. 
CHANDAN, R.C. 1999. Enhancing market value of milk by adding cultures. J. Dairy Sci. 82, 2245-2256.

CHANDAN, R.C. and SHAHANI, K.M. 1993. Yogurt. In Dairy Science and Technology Handbook, Vol 2 (Y.H. Hui, ed.) pp. 1-56, VCH Publisher, New York, NY.

CHANDAN, R.C. and SHAHANI, K.M. 1995. Other fermented dairy products. In Biotechnology, 2nd Ed., Vol 9 (G. Reed and T.W. Nagodawithana, eds.) pp. 386-418, VCH Publisher, Weinheim, Germany.

ÇON, A.H., ÇAKMAKÇI, S., ÇAĞLAR, A. and GÖKALP, H.Y. 1996. Effects of different fruits and storage periods on microbiological qualities of fruit-flavored yogurt produced in Turkey. J. Food Prot. 59, 402-406.

CVETAN, D. 1998. Yogurt gaining niche in American culture. Dairy Field 181(4), 23-26.

ESTEBAN-DIEZ, I., GONZALEZ-SAIZ, J.M. and PIZARRO, C. 2004. An evaluation of orthogonal signal correction methods for the characterization of Arabica and robusta coffee varieties by NIRS. Anal. Chim. Acta $514,57-67$.

GASSEM, A.M. and FRANK, F.J. 1991. Physical properties of yoghurt made from milk treated with proteolytic enzymes. J. Dairy Sci. 74, 1503-1511.

GORSKI, D. 1997. Cultured product trend. Dairy Foods 98(4), 33-34.

HAUSLER, W.J. 1974. Standard Methods for the Examination of Dairy Products, 13th Ed., American Public Health Association, Washington, DC.

INTERNATIONAL DAIRY FOODS ASSOCIATION. 1997. Milk Facts, International Dairy Foods Association, Washington, DC.

KARAGÜL-YÜCEER, Y., COGGINS, P.C., WILSON, J.C. and WHITE, C.H. 1999. Carbonated yoghurt-sensory properties and consumer acceptance. J. Dairy Sci. 82, 1394-1398.

KEATING, K.R. and WHITE, C.H. 1990. Effect of alternative sweeteners in plain and fruit-flavored yogurts. J. Dairy Sci. 73, 54-62.

KORA, E.P., SOUCHON, I., LATRILLE, E., MARTIN, N. and MARIN, M. 2004. Composition rather than viscosity modifies the aroma compound retention of flavored stirred yogurt. J. Agric. Food Chem. 52, 30483056.

KURMANN, J.A., RASIC, J.L. and KROGER, M. 1992. Encyclopedia of Fermented Fresh Milk Products, Appendix E, Van Nostrand Reinhold, New York, NY.

LABELL, F. 1989. Yoghurt cultures offer health benefits - Biotechnology to transform the yoghurt of the future. Food Processing 50, 130-138.

LAYE, I., KARLESKIND, D. and MORR, C.V. 1993. Chemical, microbiological and sensory properties of plain nonfat yogurt. J. Food Sci. 58, 991-995. 
LUBBERS, S., DECOURCELlE, N., VALLET, N. and GUICHARD, E. 2004. Flavor release and rheology behavior of strawberry fatfree stirred yogurt during storage. J. Agric. Food Chem. 52, 3077-3082.

NASS. 2006. Dairy Products. National Agricultural Statistics Service, US Department of Agriculture. www.nass.usda.gov (accessed September 20, 2006).

ORGISH, S. 2002. Market report on the refrigerated yogurt market in the USA. http://www.swissemb.org/trade/download/YogurtMarket.pdf (accessed September 22, 2006).

ÖZTÜRK, B.A. and ÖNER, M.D. 1999. Production and evaluation of yogurt with concentrated grape juice. J. Food Sci. 64, 530-532.

RENNER, E. and SALDAMLI, I. 1983. Fermented dairy products in view of nutrition. Gida 8, 297-311.

RODARTE, C.W., GALVAN, M.V., FARRES, A., GALlARDO, F., MARSHALL, V.E. and GARIBAY, M.G. 1993. Yoghurt production from reconstituted skim milk powders using different polymer and nonpolymer forming starter cultures. J. Dairy Res. 60, 247-254.

SAS. 1998. SAS/STAT Guide for Personal Computers, Version 6.12, SAS Institute, Cary, NC.

SHAHANI, K.M. and CHANDAN, R.C. 1979. Nutritional and healthful aspects of cultured and culture-containing dairy foods. J. Dairy Sci. 62, $1685-1694$.

SHARF, J.M. 1966. Recommended Methods for the Microbiological Examination of Foods, American Public Health Association, Inc., New York, NY.

SPECK, M.L. 1976. Compendium of Methods for the Microbiological Examination of Foods, American Public Health Association, Washington, DC.

TAMIME, A.Y. and MARSHALL, V.M.E. 1997. Microbiology and Biochemistry of Cheeses and Fermented Milks, pp. 57-152, Blackie, London, U.K.

TAN, S. and ERTÜRK, E. 2002. Condition and Estimated Report of Milk and Dairy Products, Agricultural Economics Research Institute, Ankara, Turkey.

TURKISH FOOD CODEX. 2000. Official Bulletin of Raw Milk and HeatTreated Milk, No 2000/6, Ministry of Agriculture and Village Affairs and Ministry of Health, Ankara, Turkey.

TURKISH FOOD CODEX. 2001. Official Bulletin of Fermented Milks, No 2001/21, Ministry of Agriculture and Village Affairs and Ministry of Health, Ankara, Turkey.

TURKISH STANDARDS INSTITUTE. 1989. Yoghurt Standard (TS 1330), Turkish Standards Institute, Ankara, Turkey.

VICKERS, Z., HOLTON, E. and WANG, J. 2001. Effect of ideal-relative sweetness on yogurt consumption. Food Qual. Pref. 12, 521-526. 